\title{
Master Degree Modules in Nanotechnologies for Electronics
}

\author{
http://dx.doi.org/10.3991/ijoe.v8i2.1925 \\ S. Tzanova \\ Technical University of Sofia, Sofia, Bulgaria
}

\begin{abstract}
The paper presents an European project focusing on closer cooperation in the university sector and transparency of qualifications and recognition methods. It is aimed at common MSc degree level courses development for the new skills for new jobs in the multidisciplinary nanoelectronics and a new job organisation.
\end{abstract}

Index Terms-nanoelectronics, technology, e-learning, curriculum, European project.

\section{INTRODUCTION}

There are few individual research teams, laboratories or companies that can claim to be able to respond to the technological challenges. To meet these needs in this project three (four with HEIG-VD from Switzerland) European universities share infrastructure, technological and human resources and will recognise the common, based on ECTS, certified modules, to be used in the partners' MSc programmes in nanotechnologies.

\section{Why WAS ThIS PROJECT DESIGNED?}

The project focus is on common MSc degree level courses development for the new skills for new jobs in the multidisciplinary nanoelectronics and a new job organisation. The problems and the needs are best identified in [1]: "In knowledge-intensive and growing sectors such as nanotechnology, there will be even greater demand for scientists skilled in more than just one area of research. The shortage of European scientists may hamper growth in these sectors and result in the relocation of knowledgeintensive activities." and "The studies in this area (nanoelectronics) point to the urgent need to further develop scientific education and training with a particular stress on interdisciplinarity."[2]

"Technological change also influences the organisation of work, which affects the demand for different levels of skills. Work organisation is now characterised by decentralised decision-taking, just-in-time operation, job rotation, teamwork and multitasking. The OECD [3] has paraphrased this as 'high-performance work practices', emphasising that these new requirements lead to higher skill needs." And the conclusions of DG EMPL project [4]: "For some job functions special courses are needed. It is necessary to strike a balance between what is offered in the educational system and what is needed in the sector."

So, the shortage of engineers in nanotechnology and the systematic decrease of students in the field can be a threat to the European economy competitiveness. There are few individual research teams, laboratories or companies that can reasonably claim to be able to respond to the technological challenges. Even the big companies in the sector work with a common use of R\&D resources (as Motorola \& ST Microelectronics etc). No one university can afford the necessary infrastructure, clean rooms, technology and experts in all fields of the multidisciplinary science of nanotechnology.

\section{OBJECTIVES}

This project focuses on sharing the technological and human resources available at each partner university to develop teaching modules/courses in the highly interdisciplinary area of nanotechnology; certified, based on ECTS, to be used in the partners' MSc programmes in nanotechnologies.

Its specific objectives are:

- To analyse the educational needs in nanoelectronics and nano-bioelectronics through problem and job analysis, and to define the necessary knowledge, skills and competencies of engineers in the sector in terms of learning outcomes.

This objective addresses the need of definition of new skills for new jobs in nanoelectronics and the needs of improvement of transparency of qualifications.

- To design syllabi and course content for regular and continuing education for master degrees in nanoelectronics and nano-bioelectronics based on ECTS and recognised in all partner countries.

This objective targets the interdisciplinary sector of nanotechnologies and the needs of closer cooperation in the university sector using the infrastructure, technology and expertise of partners' universities.

- To develop lessons for higher order skills and learning materials for e-learning mode of delivery.

This objective addresses the needs of skills and competences for 'high-performance work practices' in the new work organisation.

- To develop lessons for practical work in the high-tec laboratories of partner institutions as a part of the partners' MSc degree programmes.

This objective addresses the need of sharing an expensive infrastructure, clean rooms maintenance, technology and even experts in all fields for effective education in the multidisciplinary science of nanotechnology.

- To start the implementation of the joint modules/courses delivery.

This objective addresses the necessity of striking a balance between what is offered in the educational system and what is needed in the sector. 


\section{TARGET USERS}

Within the presented project we target the following groups of users:

- Students in micro- and nanoelectronics.

They need high-quality educational materials, and continually brought up-to-date courses, because of the essence of nanotechnologies - the most rapidly advancing sector now a day. They need education related to their further work and for the complexity of the knowledge and skills, necessary to perform successfully the tasks in this multidisciplinary science determines the needs of "practical training”.

- Their teachers.

They need infrastructure, modern equipment and facilities for teaching nanotechnologies, they need techniques for course delivery allowing easy changes and upgrade because of the fast developing science of the subject matter, i.e. ICT-based materials.

- University management.

It is convinced of the necessity of European dimensions in higher education, particularly with regards to curricular development, interinstitutional cooperation, virtual mobility of students and academic staff, and integrated programmes of study, training and research.

From institutional point of view the targets are the higher education institutions providing accredited MSc. degrees in micro- and nanoelectronics. As no one university can afford the extremely expensive infrastructures, equipment and maintenance of clean rooms for nanotechnology, collaboration and sharing of facilities and teachers' expertise is of high institutional interest for the universities.

\section{PROJECT PARTNERS}

The project consortium includes highly qualified university teachers and researchers in the field of nanotechnologies, and experts in educational technology as well.

The Politecnico di Torino training and research interests are in all ICT fields, ranging from higher-level systems up to the circuit and device level. It includes related areas, such as micro- nano- systems and application fields as bioengineering. In these particular areas, the activities consist in the fabrication of silicon-based microsystems and nanosystems, fundamental research in material science, processes for micro and nanotechnology. In these topics, educational programmes are several, starting from the contribution in the Master Degree in Nanotechnologies, up to the offer of courses in Politecnico di Torino faculties as "CAD for Microsystems", "MEMS/NEMS Applications" or "Microsy/Nano sytems for Medicine”.

The Department of Microelectronics at the Technical University of Sofia is a national technological centre in micro- and nano-technologies. It offers teaching programs, research opportunities, and industrial collaboration in electronics, microsystems and semiconductor science and technology. The practical training will be performed in the ECAD laboratory and in collaboration with the National Centre for Nanotechnologies at the Academy of Sciences. ECAD Laboratory is a National information and training centre in design of ICs, microsystems etc. The activities of the TeLEARN laboratory focus on the inte- gration of eLearning, knowledge management, and electronic performance support systems.

PHELMA, the PHysics, ELectronics and MAterials engineering school of Grenoble Institut National Politechnique offers master level courses on various topics related to nano-technolgies: nano-electronics, bio-technologies, nano-structures analysis... CIME Nanotech (Centre Interuniversitaire de Microelectronique) provides all needed resources (human and technical) for training, education and research in microelectronics to the needs of all French higher education and SMEs. It offers all the required environments for design, process and measurements in micro and nanotechnologies.

The countries in the EU Lifelong Learning Programme are three but the project partner countries are five with HEIG-VD , Switzerland and Tel Aviv University, Israel.

All organisations provide MSc degrees in micronanoelectronics, they have national accreditation and can provide certificate for the courses. The three LLP partners have experience in ERASMUS mobility programmes and delivering courses with credits based on ECTS is not new for them. New is the e-learning delivery of the more theoretical part of the courses.

\section{CURRICUlum DESIGN APPROACH}

Because of the differences of national lows in each country, we considered that at this stage planning accreditation of joint or multiple MSc degrees for the next two years is not realistic.

Each course is being designed by the best laboratory/ department in the field with the necessary infrastructure and facilities for practical work. After successfully passing the test of the e-learning course, the students will perform the practice in the partners' laboratories, followed by practical assessment. The mobility will be no more than a week of practice.

Each course is designed for specific learning outcomes, with credits for each course unit to be given after assessment, and adopted by all partner institutions. These credits will be transferred to the MSc programme at the partner university where the student is enrolled. ECTS credits are fully recognised but the grades according to the norms of the country are still required, a system for transfer of local grades in the 5 countries will be set.

The first courses under development are:

- NANO structures characterisation

- Biochips - DNA microarray technology

- Design of nanoscale ICs

- Defaults and non-invasive testing of nanodevices

- Nanogaps

- Characterization of nanostructures and carbon nanotubes

Quality assurance (QA) is an integral part of the internal management of all partner institutions following the standards in the European Higher Education Area and the new courses will be objects of these QA procedures.

So, the universities will share their infrastructure, technological and human resources, they will recognise the courses/credits but each university will keep his autonomy regarding the national diploma delivery. To facilitate the implementation of the results during the project lifetime, the new courses will be added to the list 
the new courses will be added to the list of electives to avoid complicated procedures of a whole curriculum change in each country.

The added value for the students will be in the highest quality of the specialised courses developed by the best departments in the field, the opportunity to study more courses from the home institution and most important the opportunity to train practical skills and competences in the laboratories with advanced equipment and facilities

\section{INNOVATION}

In this project we adapt the approach of the big enterprises in the sector to share the research and development facilities and expertise despite the competition (or just to be competitive). Examples are the technology on $30 \mathrm{~cm}$ wafer - common success of Motorola and Infineon technologies.

There are common MSc degree programmes in microelectronics in which students study 6 months in each country (the MSC degree of EPLF, INPG and POLITO). These programmes require assured financing for students and teachers mobility for long periods of 6 months. And the teachers and managers of the participating institutions declared having lost their proper students.

The innovative solutions provided by this project are:

- Sharing of resources, which a single university can not afford, for improving the education in high technologies for the new jobs in nano- bionanotechnology in the LLP countries,

- Enriching the collaboration in sharing resources with - Israel and Switzerland.

- Virtual mobility: In this project the mobility is mostly virtual thanks' to the e-learning courses and only for the practical modules short student mobility of one week will be necessary. 10 courses are under development, 2 per partner institution. In traditional scheme of common degree delivery and even within Erasmus mobility programme the students need to stay 4 semesters abroad and to follow the courses delivered

\section{WORK IN PROGRESS}

The learning outcomes are being defined for each course with the corresponding credits after assessment, adopted by all partners. These credits will be transferred to the MSc programme in nanoelectronics at the partner university where the student is enrolled. So the universities will share their infrastructure, technological and human resources, they will recognise the common certified modules but each university will keep his autonomy regarding the national diploma delivery. The implementation of the joint courses will start during the third project year as a part of the regular curricula of the MSc degrees at each university.

Some examples of the course modules under development are given on Fig. 1 and Fig. 2.

Each course is being designed by the best laboratory/ department in the field which dispose with the necessary infrastructure and facilities for practical work.

The engineering education involves the use and application of skills for finding solutions, making decisions, and thinking effectively, i.e. problem-solving skills [5]. So, instructional strategies and tactics for higher-level

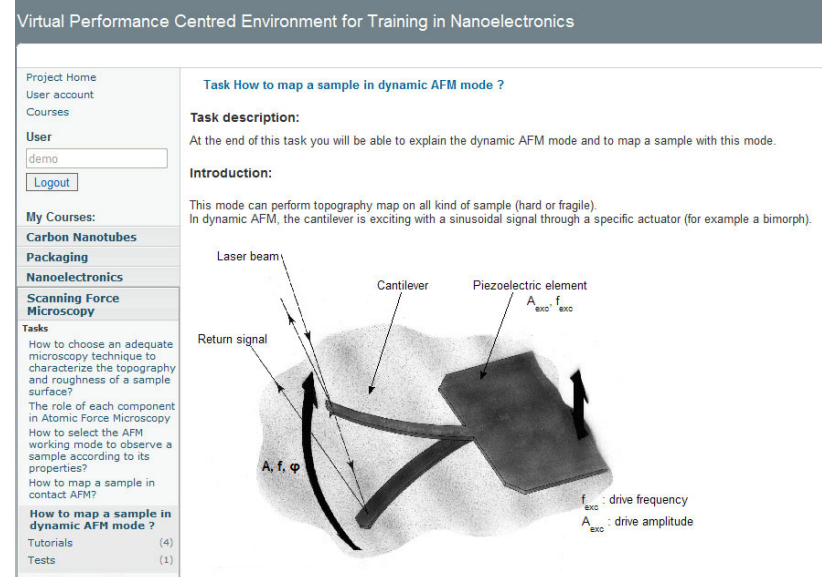

Figure 1. Example of the "Atomic Force Microscope” module

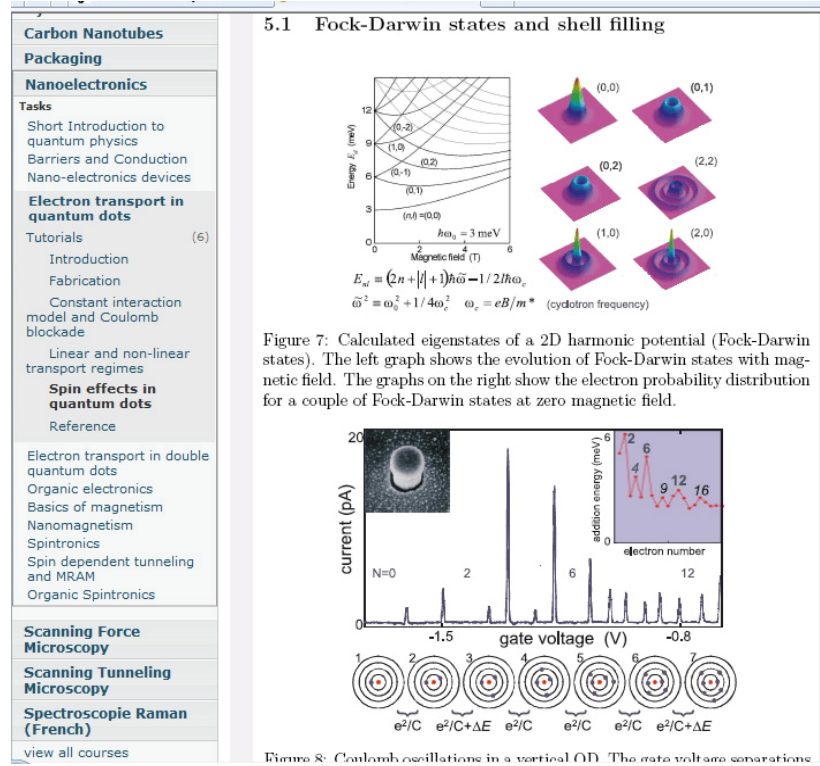

Figure 2. Example of the module "Spin effect in quantum dots"

skills are being used in the course design. In this project discovery inductive strategy is implemented (when it is possible from pedagogical point of view) in an interactive Web-based instruction (related most to problem-solving).

Specific tasks are designed for competences training [6], [7], e.g. group work and tasks to manage a team or plan a new work organisation for implementation of new technology.

At the next stage of the project Web-based learning materials are being developed and professional videos of some lectures and of the practical work in the clean rooms and laboratories. The videos are made by the experts from Tel Aviv university. Live WebCasts of an event, with an interactive talkback facility, can further enhance the quality of the experience. Such a portal was built by Tel Aviv University for European NOE Nano2Life (http://n2lvip.tau.ac.il) and maintained during the whole life cycle of the project. The site as it is at the moment content around 300 lectures on Nano bio topics.

\section{The NANOEl Courses AND LABS}

The final goal of NanoEl is the student mobility, and the transfer of the students to external Universities is done 
for the practical work (Hands-On sessions), else the theoretical preparation and the study of what will be done in the laboratory sessions are done remotely, strongly using e-learning platforms. With this approach, the setup of a network of universities where the laboratories can be done, opens a lot of new possibilities. In fact for the students of one university is possible to do hands-on laboratories with instrumentations and expertise not present in their own place. They can study and be prepared in advance staying at their own institutes, and then they can move only for the practical works, saving time and expenses, but having a special experience, not possible if they were staying at home.

The laboratory exercises are developed using different methodologies. In the first training step, the necessary theoretical preparation is based on recorded material, published in the NanoEl website. Then, the laboratories are presented in different ways, depending on the goal of the work to be executed by the students:

a) The laboratory is live recorded and, in case it would be helpful, some supporting slides are showed on one half of the screen, and on the remaining screen section the practical operations are presented

b) In case of a use of a CAD tool, the screen where the work is executed is recorded, and all the steps are commented

c) A fully web-based laboratory is implemented, and all the laboratory is executed through a web browser

\section{A. Laboratory live recording}

One of the laboratories developed in NanoEl, based on live recording, is the experimental fabrication of nanogaps. In this laboratory custom electronic boards are used as control of the fabrication of the nanogaps. These boards are connected to a silicon chip, where some gold wires are pre-deposited, in which the nanogaps are created by electromigration. All the fabrication process is controlled by software application. So, in the laboratory different parts are present: PCB boards, a silicon chip and a software control.

All these parts are presented in a video where, as can be seen in Fig. 3, slides and live demonstration of the devices are done together, allowing to the student to have a precise perception of which are the components involved in the hands-on work and in the meantime the practical procedures are clearly explained.

In another module developed in NanoEl, within the course on Carbon NanoTubes (CNTs) and their use in nanoelectronics, a video related to the preparation of the CNTs was recorded. In that recording it is practically shown which are the steps in a laboratory to fabricate CNT electrodes.

\section{B. CAD tool tutorial}

In courses on nanoelectronics, working at molecular level is an important topic to consider. For this reason in one of the NanoEl courses some CAD tools for simulation at molecular level are examined, Gaussian and Atomistix Virtual NanoLab.

For the training about the use of the software a tutorial, with the step-by-step tool configuration and simulation of a simple structure, is produced in a video (Fig. 4). The result is a merge of slides, practical work on the software and comments of simulation results.

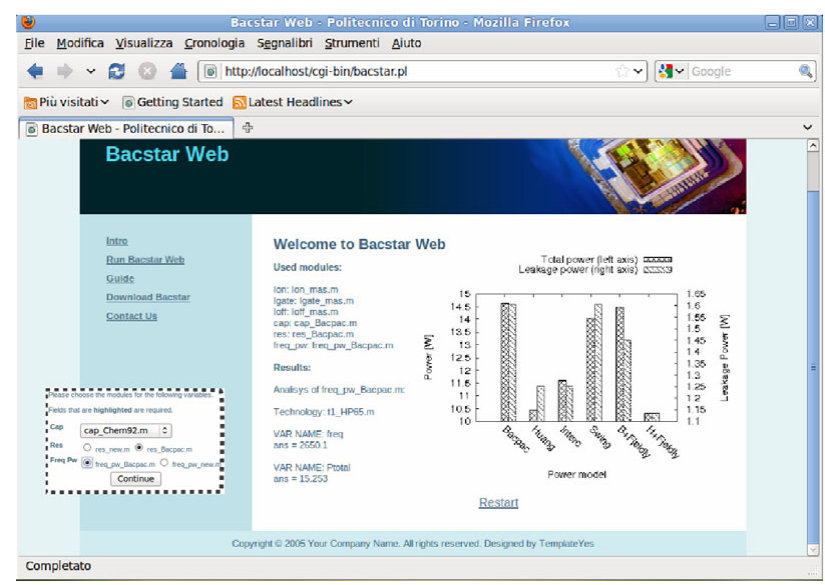

Figure 3. Screenshot of a WEB based Lab

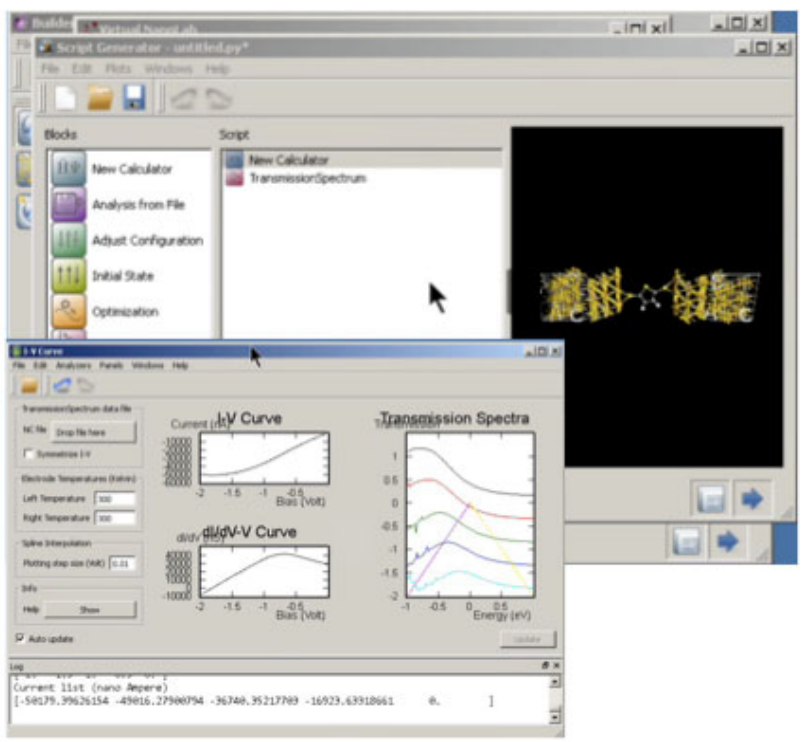

Figure 4. CAD tool tutorial

With this approach it becomes possible to the student to have a clear idea of how to use the software and to learn the basics like being in a real laboratory, so they will be prepared and more effective to work on the hands-on exercises in the lab rooms.

\section{WEB based laboratory}

One of the course developed is on the trend of technology for microelectronics, starting from the analysis of 100 $\mathrm{nm}$ to $20 \mathrm{~nm}$ nodes and concluding with novel beyond CMOS technological solutions (SET, CNFET, MOFET, CNT Wires ...). Currently very few laboratories can afford teaching these subjects in the micro and nanoelectronics teaching scenario. Practical exercises are provided by a WEB based tool (Fig. 4) for the analysis and the impact of technological choices at device and system level, both for CMOS and beyond CMOS structures.

Three are the main learning phases:

1. for standard ultra-deep-sub-micron CMOS processes the tool allows the analysis of the impact at device level of technological choices;

2. for process to system level performance the tool increases the knowledge on the impact at system level of technological and device choices and parameters; 
PAPER

3. for the beyond CMOS processes the tool enables the analysis of the impact at device and at system level of emerging technologies fabrication techniques and properties.

An example of the tool is shown in Fig.5. It has been developed ad hoc, inspired to MASTAR [8] and BACPAC [9]. It is based on Octave (Open Source) scripts and includes the most advanced models of deep submicron and post-CMOS devices available in literature and from industry. To allow the maximum grade of flexibility, during the set up of the analysis it is possible to choose the technological nodes where the modules will be evaluated. After this selection it is possible to choose the modules that must be calculated (example: Ion, Igate, Ioff, Ibtb of a transistor, crosstalk between interconnects, system level power consumtion,....). However, the evaluation of certain modules requires the previous calculation of other modules (i.e. certain models of Ioff are calculated starting from the value of Ion). A special system is implemented to handle this parameter interdependency. These results can be shown in two ways, with a graph or with a table, and they can also be exported on a file. Many modules can be evaluated on the same graph or table (up to 12 modules together). This allows an easy comparison between different models.

\section{IPlementation, Pilot Test}

The courses developed in this project will enter as elective courses with the corresponding credits based on the ECTS in the regular curricula of the MSc degrees in each partner university. So, not all students will study all courses but minimum 15 students per partner institution will be involved in the pilot test. First the e-learning courses (each one for 3 months) will be delivered with distant tutoring (e-mail, Skype, Flashmeeting for group sessions). After successful test on the e-learning module of each module the learners could make the practical work in the clean rooms available in the partner universities. The student mobility will be for maximum 1 week.

The practical modules assessment will be with practical tests and will depend on the results of the tasks to be performed in the laboratory.

After successful assessment the student will obtain a certificate with the corresponding credits and the local grade of the host institution system with corresponding grade of the student's home institution system.

Questionnaires and interviews will be used to measure the students and teachers attitudes, satisfaction, to reveal problems if any and to improve the courses and the collaborative MSc degree courses delivery.

\section{EXPECTED IMPACT}

We expect an impact of this curriculum development project on:

- the approach: in sharing facilities and expertise of four European universities in the new science of nanotechnology to provide the best education for the new jobs in the sector.

- the target groups: the contribution for the students will be in the highest quality of the specialised courses developed by the best departments in the field, the opportunity to study more courses from the home institution and most important - the opportu- nity to train practical skills and competences in the laboratories with advanced equipment and facilities;

- the educational system: each university "keeping” its MSc students and at the same time the students and the teachers profit from the collaborative curriculum; improvement of university engineering education through innovation of educational curricula with the newest scientific and technological content and clearer relationship between learning processes in the university and at the real workplace.

\section{SUMMARY}

In this manuscript we presented a work in progress within the European community project "Master Degree Modules in Nanotechnologies for Electronics". The project is aimed at common MSc degree level courses development for the new skills needed for the new jobs in the multidisciplinary nanoelectronics and a new job organisation. At this very early stage in the project lifecycle we have defined the learning outcomes and selected the first courses and their content design is under development.

\section{REFERENCES}

[1] New Skills for New Jobs, matching labour market and skills needs, Communication from the Commission to the European Parliament, the Council, the European Economic and Social Committee and the Committee of the Regions, $\{\mathrm{COM}(2008) 868$ final $\}$

[2] Eurofound, European Monitoring Centre on Change (2008), 'The future of the European biomedical healthcare sector: Four scenarios'.

[3] OECD Employment Outlook 1999.

[4] Investing in the Future of Jobs and Skills Scenarios, implications and options in anticipation of future skills and knowledge needs, DG EMPL project VC/2007/0866, “Comprehensive Sectoral Analysis of Emerging Competences and Economic Activities in the European Union”. Lot 7, Sector Report, Computer, Electronic and Optical Products, May 2009.

[5] S. Tzanova. An European Project for Internet-based Performance Centred Instruction in Microelectronics Proc. Conference on Educational Multimedia, Hypermedia \& Telecommunications, Montréal, 2005, 215-218.

[6] Tzanova S., Codreanu N., Training Microsystems Technologies in an European eLearning Environment, The Future of Global Learning in Engineering Education IEEE EDUCON 2010, April 14th 16th, 2010, Madrid, ISBN 978-1-4244-6569-9, pp. 113-118.

[7] Martínez-Mediano, C.,Castro, M., Mileva, N.; Stoyanov, S., Kicken, W., Díaz, G., Riopérez, N., Tzanova, S., San Cristóbal, E., Martín, S., Internet-based Performance-centered Learning Environment for Curriculum Support and its application in mLearning, The Future of Global Learning in Engineering Education IEEE EDUCON 2010, April 14th - 16th, 2010, Madrid, ISBN 978-14244-6569-9, pp. 819-824.

[8] MASTAR (Model for Assesment of CMOS Technologies And Roadmaps) available free of charge, ST-Microelectronics courtesy; available on ITRS web site

[9] D. Sylvester and K. Keutzer “'System-Level Performance Modeling with BACPAC - Berkeley Advanced Chip Performance Calculator," Proc. of IEEE SLIP, 1999, pp. 109-114

\section{AUTHOR}

S Tzanova is with the Technical University of Sofia, Department Microelectronics, 8 Kliment Ohridski blvd., 1000 Sofia, Bulgaria (e-mail: slavka@ecad.tu-sofia.bg).

This project is funded with support from the European Commission, ERASMUS "Master Degree Modules in Nanotechnologies for Electronics”, project 510196-LLP-1-2010-1-IT-ERASMUS-ECDCE. Manuscript received 8 January 2012. Published as resubmitted by the author 27 April 2012. 